\title{
Climate Change and its Implications for Development: The Role of IPCC Assessments
}

\section{R.K. Pachaurí}

The Intergovernmental Panel on Climate Change (IPCC) was established in 1988 jointly by the World Meteorological Organisation (WMO) and the United Nations Environment Programme (UNEP) and its establishment was subsequently endorsed by the UN General Assembly. The IPCC provides the climate change regime with authoritative assessments, undertaken in a comprehensive, objective, open and transparent manner, of the scientific, technical and socio-economic information relevant to understanding climate change, including its impacts and mitigation. The IPCC has brought out three such assessment reports: the First Assessment Report (1990) set the stage for the negotiations of the UN Framework Convention on Climate Change, the Second Assessment Report (1995) provided the impetus for the negotiations of the Kyoto Protocol and the Third Assessment Report (2001) laid the scientific basis for continued international cooperation. Work on the Fourth Assessment Report is currently in hand, and is due to be completed in 2007. In organising these successive efforts, the IPCC mobilises experts and specialists working on various aspects of climate change drawn from all over the world, to ensure that not only is there a geographical balance in the expertise that is provided towards production of each assessment, but also to employ the widest possible range of knowledge and expertise for this purpose.

The Fourth Assessment Report would, as in previous assessments, access current literature in the field and provide the latest knowledge available, which it is hoped will fill up some of the gaps in the earlier assessments and appropriately update the information and analysis contained in them to reflect recent work available in the literature. One of the major features of the Fourth Assessment Report would be the inclusion of a set of cross cutting themes, which include, among other subjects, the nexus between climate change and sustainable development as well as integration of adaptation with mitigation options. There is, therefore, an intention to build development issues into the next assessment in a manner that is relevant to the impacts of climate change on various aspects of economic development in different parts of the world. The Third Assessment Report (TAR) clearly identified the areas in which critical natural resources, fragile ecosystems and important economic activities would be likely to suffer unfavourable consequences. Figure 1 shows, in summary form, major types of impacts of climate change including sea level rise.

As it happens, some of the most vulnerable societies would be the ones that have the lowest capacity to cope with the impacts of climate change. The TAR assessed that 'the impacts of climate change will fall disproportionately upon developing countries and the poor persons within all countries, and thereby exacerbate inequities in health status and access to adequate food, clean water and other resources'. If climate change is to take place as projected, then the impacts created would impose a major constraint on the ability of the poor countries being able to lift themselves out of their current state of lack of development. It would be difficult to cover in detail the specific development implications of each major set of impacts of climate change. Hence in this brief article, the focus is confined to looking at some of the broad implications for agriculture in the developing world in the context of climate change with a particular focus on recent work undertaken in India. These are significant because of the changes that are likely to take place in the quantity and quality of water supply resulting from changes in precipitation, the effect of higher temperatures on several crop species as well as the impacts on soil quality. 
Figure 1: Impacts of climate change

\begin{tabular}{|c|c|c|c|c|}
\hline & & $\begin{array}{l}\text { Temperature } \\
\text { Sea level rise } \\
\text { Precipitation }\end{array}$ & & \\
\hline & & Impacts & & \\
\hline $\begin{array}{l}\text { Health } \\
\text { Weather-related } \\
\text { mortality } \\
\text { Infectious } \\
\text { diseases } \\
\text { Air-quality } \\
\text { respiratory } \\
\text { illnesses }\end{array}$ & $\begin{array}{c}\text { Agriculture } \\
\text { Crop yields } \\
\text { Irrigation demands }\end{array}$ & $\begin{array}{l}\text { Water resources } \\
\text { Water supply } \\
\text { Water quality } \\
\text { Competition for } \\
\text { water }\end{array}$ & $\begin{array}{l}\text { Coastal areas } \\
\text { Erosion of } \\
\text { beaches } \\
\text { Inundation of } \\
\text { coastal lands } \\
\text { Additional costs to } \\
\text { protect coastal } \\
\text { communities }\end{array}$ & $\begin{array}{c}\text { Species and } \\
\text { natural areas } \\
\text { Loss of habitat } \\
\text { and species } \\
\text { Cryosphere: } \\
\text { diminishing } \\
\text { glaciers }\end{array}$ \\
\hline
\end{tabular}

Source: GRID Arendal (United Nations Environment Programme office in Norway)

Agriculture still provides the largest source of employment in most developing countries including China and India where approximately two-thirds of the population is dependent on agriculture. For illustrative purposes, therefore, this article provides some insights from work done recently on the impacts of climate change on agriculture in India. In several nations of the developing world, agriculture remains the largest global contributor to GDP. Assessments of climate change also need to focus on the implications for global food security. There are growing concerns on the ability of global agriculture to meet the demand for food and fibre for an expanding population, particularly in the developing countries. These concerns also arise from the fact that already there is in evidence a deceleration in the yields of rice in Asia, where the largest growth in population is projected to take place (see Devereux and Edwards, this Bulletin, for detailed discussion on food security concerns in Africa). The reasons for this decline do not lie in climate change, but are, e.g. the result of growing water scarcity, inefficient and excessive use of chemical inputs and a greater reliance on a narrower genetic base, which makes crops vulnerable to attack by pests and disease. The impacts of climate change, however, would exacerbate these trends. A decline in agriculture would lead to reduced incomes for rural populations, which include the largest number of poor people and, therefore, climate change could adversely affect programmes for the removal of poverty.
Another serious impact of climate change would be in the form of altered precipitation rates, which could increase intensity of rainfall, particularly during the monsoon season, leading to more severe and frequent floods in tropical and temperate Asia. This is likely to be accompanied by drier conditions in arid and semi-arid Asia. In other words, the extent and severity of droughts could increase significantly. Given the fact that a large part of agriculture in Asia is still rainfed, these problems of floods and droughts would also most likely impact unfavourably on agriculture. The Millennium Development Goals and the agreements reached at the Johannesburg Summit require the global community to meet specific targets in the provision of clean drinking water and sanitation facilities. Programmes to achieve these goals would also be affected unfavourably by a reduction in fresh water availability, the temporal and spatial distribution of which could change significantly. Also expected are significant changes in monthly run-off regimes, which are projected to occur in most of Asia under an altered climate. Hence, one of the most important goals set in the Millennium Summit of September 2000 and the Johannesburg Summit of 2002, namely the provision of water and sanitation facilities by 2015 for at least half the population of the world, which is currently deprived in this regard, may be affected adversely by climate change (see Burton, this Bulletin). 
Figure 2: Elements of vulnerability profiles

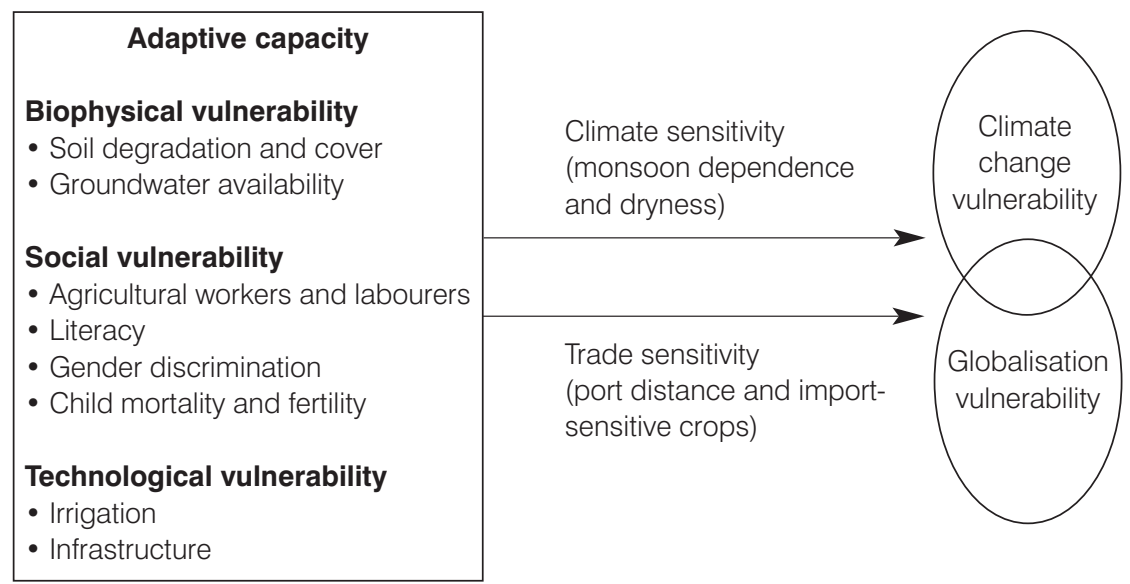

Source: TERI (2003).

The Energy and Resources Institute (TERI) has been involved in a major study to assess the vulnerability of agriculture and the options for adaptation which India has to consider seriously as a consequence of projected climate change. One of the existing factors which affects Indian agriculture is the currently unfavourable global trade regime, wherein agricultural activities in a number of developed countries are subsidised heavily, weighing against the livelihoods of poor farmers in developing countries. This would make it difficult for developing countries such as India, to pursue their current levels of agricultural activity under open market conditions. Undoubtedly, greater openness will boost efficiency and competitiveness of Indian agriculture, but it would also expose this sector to increased price volatility. Consequently, winners and losers would emerge, as different crops, farmers and regions are affected differentially by the changed conditions.

There is very little scope for India to increase its area under foodgrains. There are also limited opportunities for changes in crops, particularly in regions like West Bengal, where three rice crops are grown in succession, annually. Since agriculture is the predominant source of livelihood for a large number of peasant cultivators and agricultural labourers in that region, a shift to other occupations has serious limitations and consequences for livelihoods and development. Since such populations are characterised by low financial and technological adaptability, they are potentially vulnerable to both climate change and adverse economic changes.

The health effects of climate change could be serious in several parts of the developing world. Changes in climate could increase vector-borne diseases, apart from heat-stress related health problems. In 2003, several parts of India suffered a severe and prolonged heat wave. The worst affected region included parts of Andhra Pradesh, where during May 2003, maximum temperatures ranged from $46^{\circ} \mathrm{C}$ to $47^{\circ} \mathrm{C}$. These spells continued for a record period of 27 days and caused large scale casualties among human beings, animals and birds, particularly poultry. The poultry industry is of great importance to the state of Andhra Pradesh. The horticulture sector also suffered substantial damage. As would be expected, it was the poorest sections of society, with no options but to work out in the open under these extreme weather conditions, which suffered the largest number of casualties. The weak infrastructure for the supply of drinking water, lack of adequate information and awareness about preventive measures, and dwellings without any weather proofing arrangements were major factors responsible for illness and loss of life in this area (see also Bloom, this Bulletin). It cannot be said that the heat wave that occurred last year was in any way the result of human-induced climate change, but the TAR has assessed that climate change would also lead to greater severity and frequency of extreme weather events. The WMO has estimated that in the 
last ten years, there has been an appreciable increase in extreme weather events. It is relevant to highlight the observation of the IPCC that the 1990s have been a period much warmer than preceding decades, since recording of temperature was established.

The IPCC defined vulnerability as a function of three components, namely exposure, sensitivity and adaptive capacity. These components are of course influenced in turn by a range of biophysical and socio-economic factors. In the study undertaken by TERI, it was decided to create a profile of major parts of India, based on exposure to climate change which was seen to influence sensitivity both positively as well as negatively. It was also estimated that Indian farmers would respond to these changes depending on their capacity to adapt. Vulnerability was therefore estimated as a composite of adaptation capacity and climate sensitivity. Sensitivity was linked to exposure to climate change, based on the results provided by general circulation models. The various elements of the vulnerability profiles underlying this work are shown in Figure 2.

The results of this study were produced in the form of a map indicating climate change vulnerability of different parts of India. This measure of climate change vulnerability included an adaptive capacity index and a climate sensitivity index as defined by dryness and dependency on the monsoons, based on $0.5^{\circ} \times 0.5^{\circ}$ gridded dataset for $1961-90$ developed by the Climatic Research Unit of the University of East Anglia in the UK. The sensitivity index required some further processing based on the output from the HadRM2 down-scaled general circulation model. The resulting climate vulnerability map provided the spatial distribution of vulnerability in different parts of India, with some significant features. The highest level of vulnerability was, as expected, in the states of Rajasthan, Gujarat, Madhya Pradesh, and in the northern part of Maharashtra and the southern

\section{References}

The Energy and Resources Institute (TERI), 2003, Coping with Global Change: Vulnerability and Adaptation in Indian Agriculture, New Delhi: TERI Intergovernmental Panel on Climate Change, 2001, Third Assessment Report, Cambridge: Cambridge University Press

IPCC, 2001, Synthesis Report Third Assessment Report - Climate Change, Geneva: IPCC parts of Bihar and Uttar Pradesh. Areas with the lowest level of vulnerability include Kerala, Tamil Nadu, the coastal part of Karnataka and much of the coastal belt along the eastern part of India. Overall, the variations in vulnerability across regions were substantial. Development plans would necessarily have to take this picture into account, if the welfare of people in each of these regions was to be safeguarded. In other words, as a general hypothesis, it becomes important to mainstream climate change in development strategies, as is clearly justified by the estimates of vulnerability of the population in different parts of India, based on the assumption that the assessment of climate change would materialise. Indeed, the measures to be adopted to counter these forces would be essentially in the nature of identifying effective adaptation strategies and initiating their early implementation. Given the investments in infrastructure, creation and dissemination of knowledge and institutional changes required to implement them, it would be necessary to take some of these in hand with urgency in the immediate future, as discussed by Huq and Reid and by Agrawala in this Bulletin. The lags in the entire system and cycle of changes required are significant enough to justify the adoption of the precautionary principle today for meeting possible impacts of climate change over the next quarter of a century and longer.

The IPCC as a scientific body does not recommend any set of actions in this or other fields of human endeavour. But by carrying out an assessment of policy on relevant aspects of climate change, it provides the scientific basis for actions that others may determine is in the long-term interest of human society and the good health of planet earth. Climate change is thus likely to become an ever more important issue in the development community, which the IPCC hopes to engage, support and work with in the future.

IPCC, 1996, The Science of Climate Change: Contribution of WG1 to the Second Assessment Report, Houghton et al. (ed.), Cambridge: Cambridge University Press

IPCC, 1996, Climate Change, the IPCC 1990 and 1992 Assessments, World Meteorological Organization/UNEP and IPCC 